\title{
SIC-systemet \\ - løsning på den globale vandstandsstigning
}

Projektet ligger i lcesideerosionsområdet syd for Hvide Sande Havn. (Foto: Poul Jakobsen)

Af ingeniørerne Poul Jakobsen og Claus Brøgger, SIC - Skagen Innovation Center

Resultatet af SIC-projektet med miljøvenlig kystbeskyttelse udført over $11 \mathrm{~km}$ på Vestkysten mellem Hvide Sande og Nymindegab viser, at den gennemsnitlige strandhøjde fra klitfoden i kote 4 og 100 meter ud mod havet er hævet op til 1,47 meter i forhold til referenceområde 2 uden trykudligningsmoduler.

Dette er endnu en bekræftelse på projektet ved Gl. Skagen, hvor middelstrandhøjden var $47-63 \mathrm{~cm}$ højere i testområdet i forhold til referenceområderne efter 5 år

\section{Projektområdet}

Projektet er placeret $5 \mathrm{~km}$ syd for Hvide Sande havn på en $11 \mathrm{~km}$. lang strækning $\mathrm{i}$ et meget typisk læside-erosionsområde syd for Hvide Sande havn (se kortet til højre og fotoet ovenfor).

Den gennemsnitlige kysttilbagerykning i projektområdet er 2 meter om året, svarende til $330.000 \mathrm{~m}^{3}$, idet klithøjden i området er ca. 15 meter.

Projektområdet er opdelt i 3 referenceområder (1.800 meter) uden trykudligningsmoduler og 2 områder med trykudligningsmoduler rørområde 1 og rørområde 2 på henholdsvis 4.700 meter og 900 meter, (se placeringer på kortet til højre)
Kortet viser projektområdet med dets inddelinger $i$ referenceområder og rørområder. (Gengivet med tilladelse af KDI)

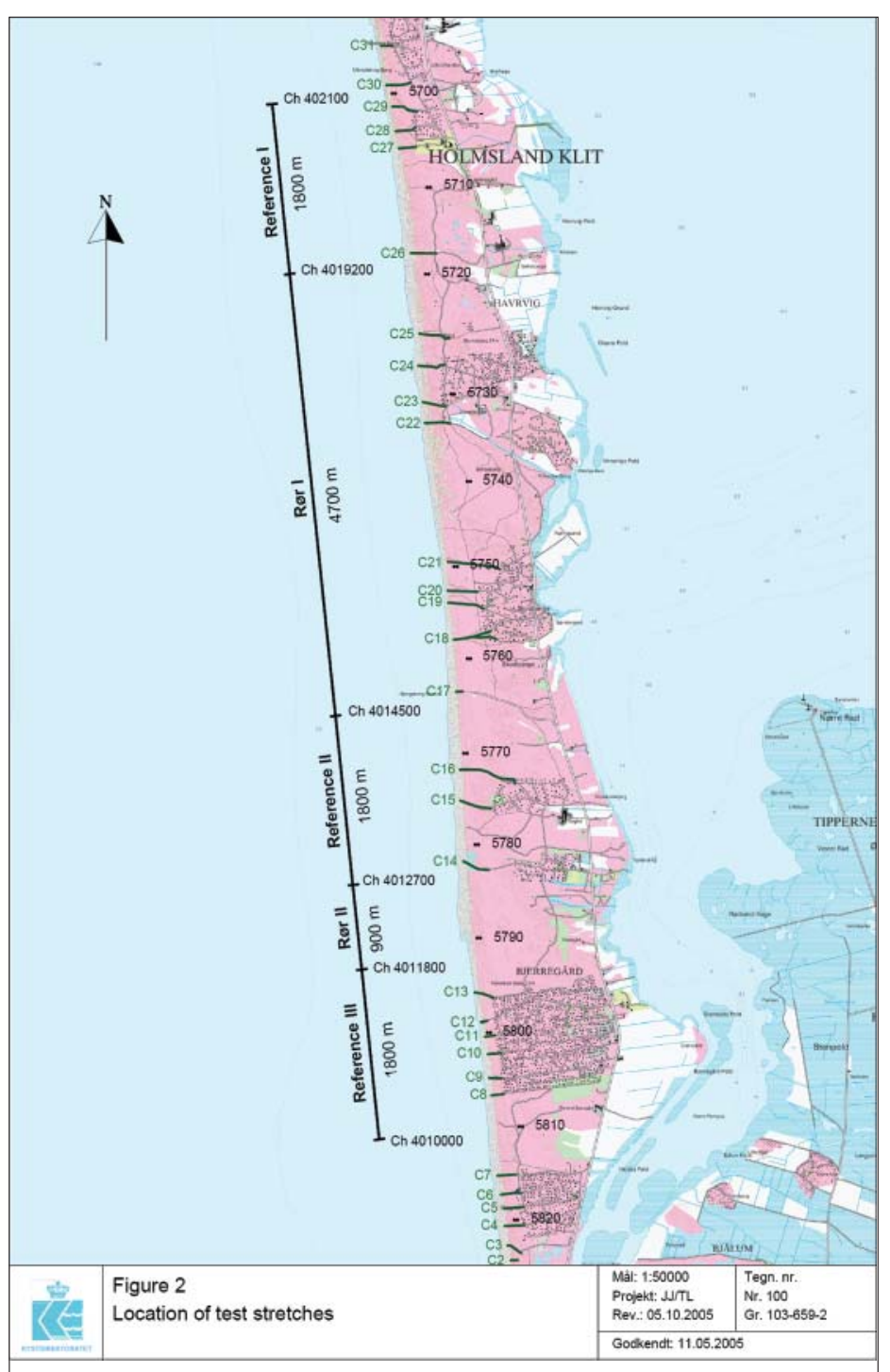


Samtidig viser resultaterne, at der er læsidetillæg ved SIC-systemet modsætningsvis hårde konstruktioner som høfder og bølgebrydere, som giver stor læsideerosion.

\section{Opbygning i forkanten af klitten}

Der er en meget nøje sammenhæng mellem vinderosionen i stranden og opbygningen af klitsystemet.

Analyser af forkanten af klitten fra klitfod kote $+4,0$ til klittop viser, at opbygningen i forkanten af klitten er ca. $55 \%$ større i de drænede områder i forhold til ref. 1 og ref. 2 (se figuren øverst til højre).

Ref. 3 er atypisk på grund af det store læsidetillæg.

Når opbygningen i forkanten af klitten alene er ca. $20 \mathrm{~m}^{3}$ pr. meter i det første år, kan man konkludere, at forstranden er sænket med minimum $20 \mathrm{~cm}$ i 100 meters bredde på grund af vinderosion.

Den årlige vinderosion i forstranden bliver nok nærmere $30-40 \mathrm{~cm}$ årligt, idet store sandmængder også lægger sig længere inde i klitterne. Dette forhold vil blive nærmere undersøgt senere.

Vi har imidlertid også registreret, at sandet fanges af den første vegetation, som sandet møder på sin vej ind i klitterne, og det er derfor formålstjenligt at plante hjælme fra kote 4 og 10 meter ud mod havet, så sandet fra forstranden ikke går tabt inde i klitsystemet. SIC har udvidet sit patent med denne løsning med en ny patentansøgning, som er indleveret i efteråret 2006.

\section{Middelstrandhøjde}

SIC har udviklet en ny evalueringsmetode, som er baseret på middelstrandhøjden i en given bredde i relation til tidevandsforskellen $\mathrm{i}$ området.

Ved Hvide Sande er tidevandsforskellen ca. 1,0 meter, og der kan opstå højvandssituationer med vandstande helt op til 3,0 meter.

Målingerne over det første år viser, at SIC-systemet genererer ca. 100 meter brede forstrande mellem Hvide Sande og Nymindegab i et balanceprofil, når stranden er drænet med SIC-systemet.

Videnskabsfolk på området anerkender generelt, at det er forstranden, som beskytter klitterne og baglandet mod kysterosion.

SIC har derfor fastlåst referencelinien til kote 4,0 meter januar 2005 og beregner middelstrandhøjden fra referencelinien og 100 meter ud mod havet (se figuren øverst på næste side).

Succeskriteriet er en middelstrandhøjde på 1,3 meter svarende til $130 \mathrm{~m}^{3} \mathrm{pr}$. meter langs stranden. I Tyskland regner myndighederne også med $130 \mathrm{~m}^{3}$ pr. meter på stranden på Sild uanset strandbredden.

Sandfodringen på den jyske vestkyst er designet til 3,5 x 70 meter, hvilket svarer til $122,5 \mathrm{~m}^{3}$ pr. meter. (Badevej Søndervig)

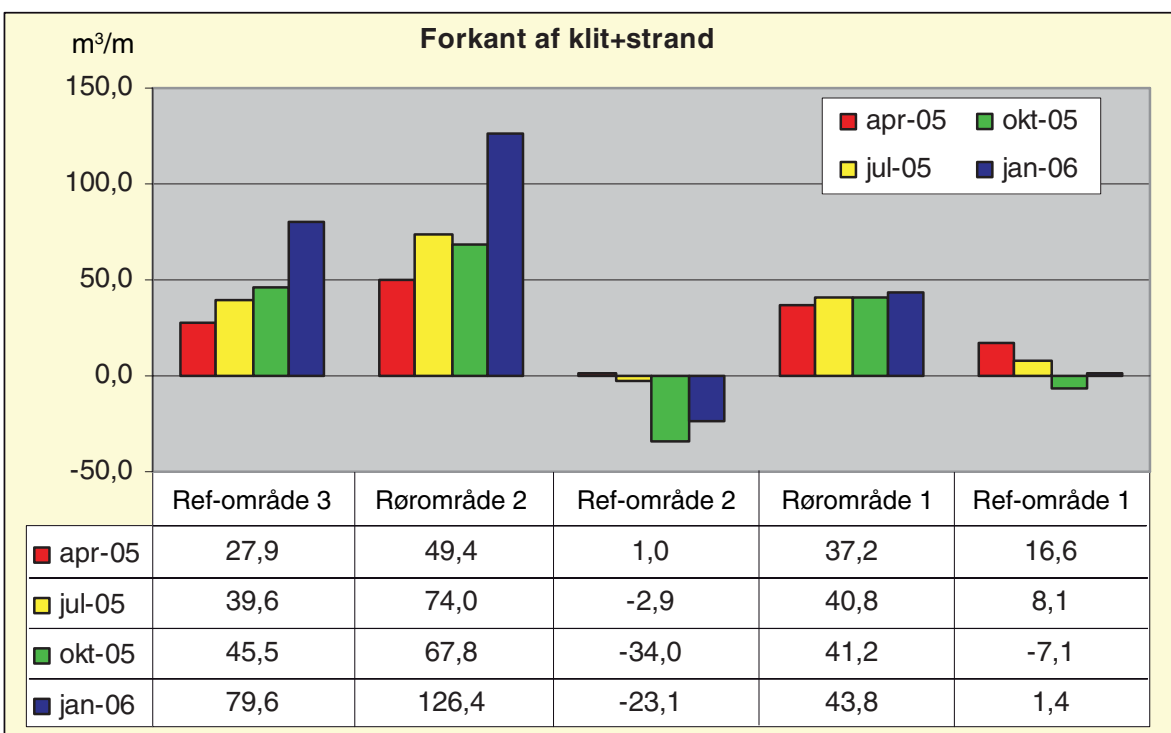

Grafen viser udviklingen på stranden og forkanten af klitten i $\mathrm{m}^{3} \mathrm{pr}$. meter langs stranden. Beregningerne er foretaget af ingeniørfirmaet Carl Bro A/S for projektgruppen. (Grafik: UVH modificeret efter udlceg af forfatterne)

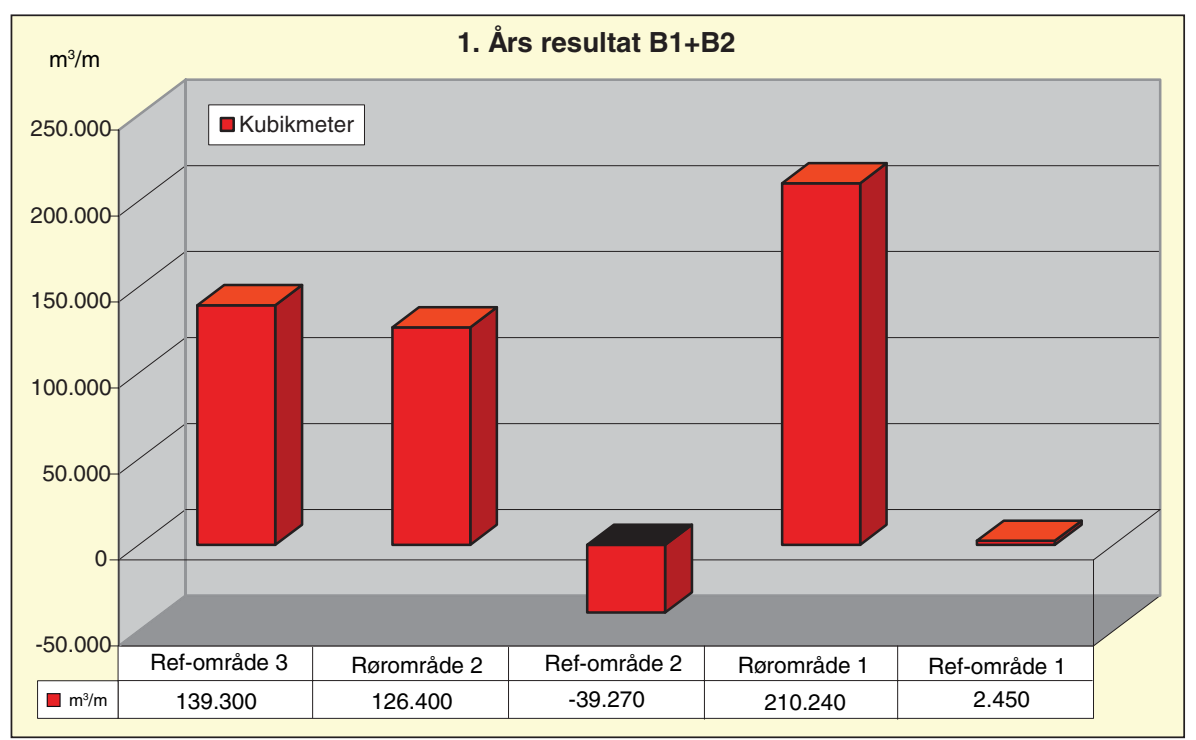

Grafen viser tillceg og erosion i forstranden (B2) og forkanten af klitten (B1) i rørområderne og referenceområderne i $\mathrm{m}^{3}$. (Grafik: UVH modificeret efter udlceg af forfatterne)

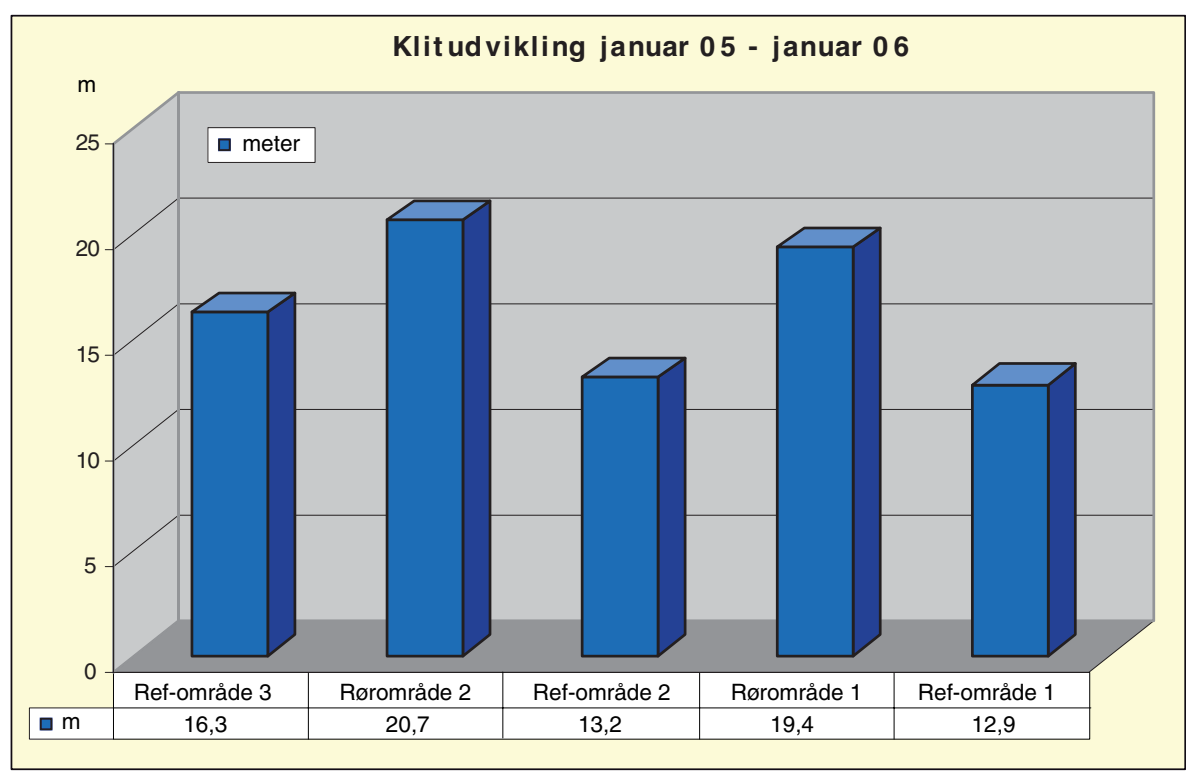

Grafen viser opbygningen i forkanten af klitten fra klitfod til klittop. Opbygningen er ca. 60 $\%$ større i de drcenede rørområder i forhold til ref. 1 og ref. 2. Ref. 3 er atypisk på grund af lcesidetillcegget. (Grafik: UVH modificeret efter udlceg af forfatterne) 


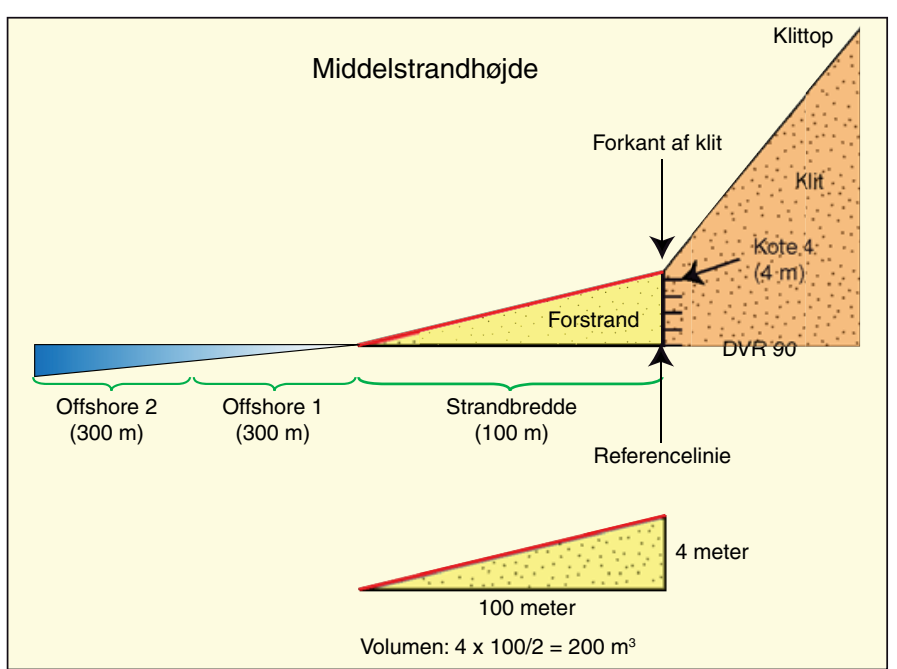

Figuren viser tværsnittet af strandprofilet og grundlaget for beregningen af middelstrandhøjden i 100 meters bredde. Det er forstranden, som beskytter baglandet i en stormsituation. (Grafik: UVH modificeret efter udlceg af forfatterne)

\section{Analyser}

I jan 2005 var ref. 2 det stærkeste profil med en middelstrandhøjde på 1,25 meter.

Ref. 2 uden drænrør er nu det svageste profil med en middelstrandhøjde på kun 0,81 meter, og havet er på vej ind gennem klitterne i ref. 2.

Modsætningsvis er strandhøjden hævet med henholdsvis 19 og $92 \mathrm{~cm}$ i rørområde 1 og rørområde 2.

Samtidig er der registreret læsidetillæg i referenceområde 3 , som resulterer i en større middelstrandhøjde i den nordlige del af ref. 3 .

Den højere middelstrandhøjde kompenserer for den globale vandstandsstigning, som er beregnet til 28 - $59 \mathrm{~cm}$ over de næste 100 år ifølge FN (ifølge UN's seneste rapport om den globale vandstandsstigning).

SIC-systemet kunne derfor være en mu- lig løsning på den globale vandstandsstigning på verdensplan.

Transport- og Energiudvalget kommer på besøg i projektområdet d. 21 marts 2007, og SIC har anbefalet Trafikudvalget, at der sideløbende etableres et anlæg på $20 \mathrm{~km}$ ved Søndervig, som skal vise effekten i stor skala.

\section{Læsidetillæg}

Referenceområde 3 ligger umiddelbart syd for rørområde 2, hvor der meget hurtigt opstod et kysttillæg på helt op til 65 meter på kystlinien, efter at stranden blev drænet $\mathrm{i}$ januar 2005 (se foto på næste side).

Når man genererer en sandtunge på kystlinien med trykudligningsmodulerne og presser kystlinien op til 65 meter ud i havet, forøger man strømhastigheden, hvilket medfører, at sandet udvasker de grove mate- rialer, som lægger sig på læsiden nedstrøms som vasket sand.

\section{Offshore}

Opmåling med Kystdirektoratets målebåd, DIGI, viser ikke erosion i havbunden ud for rørområde 1 og rørområde 2 samt referenceområde 3 .

Revlefodringen i referenceområde $1 \mathrm{og}$ nord for projektet, som man har udført i nogle år, virker ikke, men giver derimod erosion i den nordligste ende i referenceområde 1 ude i havet, og KDI (Kystdirektoratet) forsøger nu at dele revlefodringen op i længder af 1.200 meter. Der laves for øjeblikket mange forsøg med revlefodring og kunstige revler bestående af skrot mv.

I Italien vil man forsøge at bygge kunstige revler af vandretliggende betonrør.

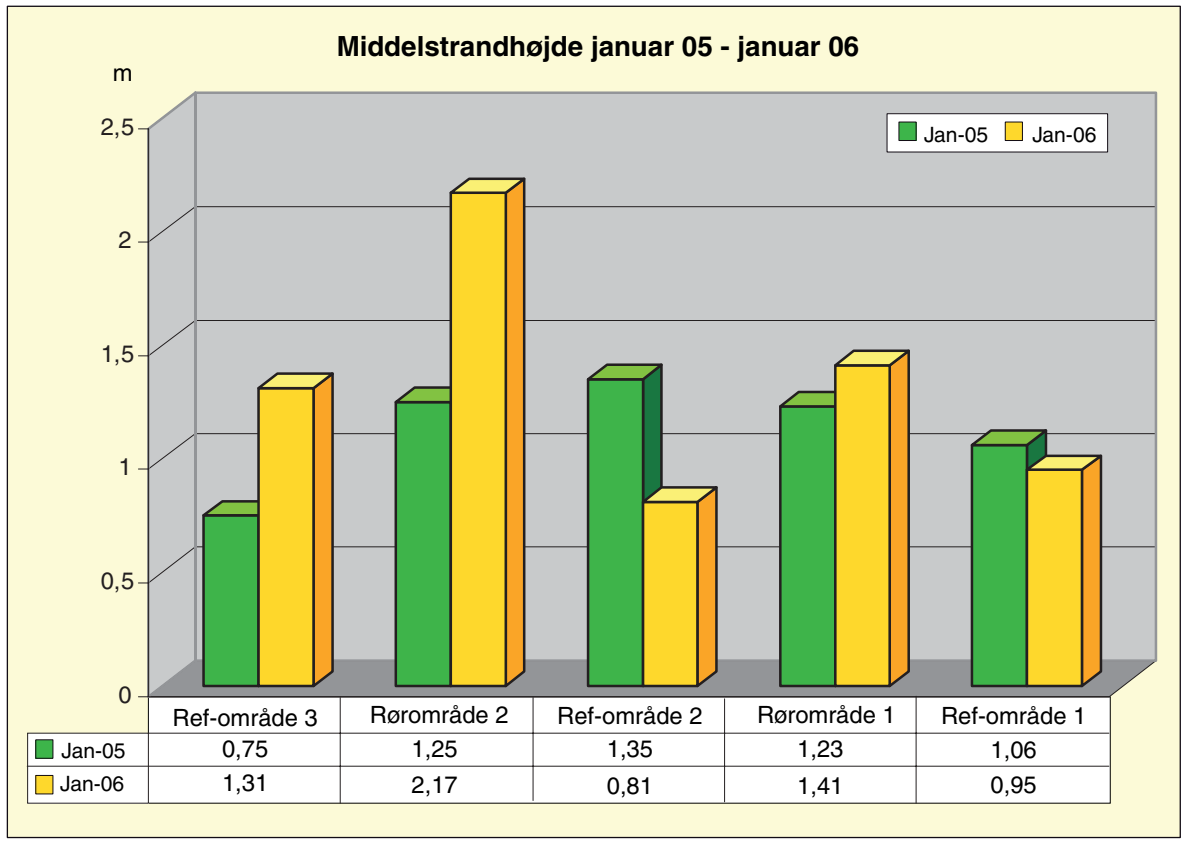

Grafen viser middelstrandhøjden fra klit foden kote +4 og 100 meter ud mod havet. (Grafik: UVH modificeret efter udlceg af forfatterne) 
